\title{
Performance ratings of impact noise insulation materials using the tapping machine and a non- standardized source
}

\author{
Desempenho de materiais resilientes utilizando a \\ máquina de impacto padronizada e uma fonte não \\ padronizada
}

\section{Andriele da Silva Panosso Stephan Paul}

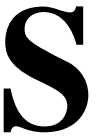

Abstract

tudies conducted up to the present moment by researchers around the world show that the evaluation of impact noise depends both on the combined system of floor and on the type of impact source used in measurements. This implies that a particular solution for reducing the impact sound pressure level could work with great efficiency when using a tapping machine and not work so well when using a different impact noise source. The objective of this study is to discuss the performance of materials against the standardized and non-standardized source, determining which of two types of sources is most efficient in simulating real cases. Results of groups measured with the non-standardized source show that all materials behave similarly and do not represent a wide range of options to solve heavy impact noise real problems as results measured with the tapping machine suggest.

Keywords: Building acoustics. Impact noise insulation. Non-standardized source.

\section{Resumo}

Trabalhos conduzidos até o presente momento por pesquisadores ao redor do mundo demonstram que a avaliação do ruído de impacto depende de dois fatores: o sistema de pisos e o tipo de fonte sonora utilizada nas medições. Isso indica que uma solução particular para reduzir o nível de pressão sonora de impacto poderia funcionar imensamente utilizando uma máquina de impacto padronizada nas medições e não funcionar tão bem utilizando um tipo de fonte de impacto diferente. O objetivo do trabalho é discutir o desempenho de materiais frente à fonte padronizada e não padronizada, determinando qual dos dois tipos de fontes é mais eficiente em simular casos reais. Os resultados dos grupos medidos com a fonte sonora não padronizada demonstram que todos os materiais se comportam de maneira similar e não representam uma grande gama de opções para resolver os problemas reais de ruído de impacto pesado como os resultados medidos com a máquina de impacto padronizada sugerem.

Recebido em 23/03/19 Aceito em 21/06/19
Keywords: Acústica arquitetônica. Isolamento acústico ao ruído de impacto. Fontes não padronizadas. 


\section{Introduction}

According to the World Health Organization, the noise generated by neighbors, classified as aerial and impact noise, is one of the biggest hassle factors in residential buildings (NIEMANN; MASCHKE, 2004). Nnoise disturbance caused by audio equipment with improved low-frequency response, electrical devices, mechanical services and mainly lightweight construction results in the aggravation of impact noise in residential buildings (ARAÚJO; PAUL; VERGARA, 2015). Among all those noises, human walking noise is considered the most annoying in residential buildings (PARK; LEE; SEOP YANG, 2016; JEON; RYU; LEE, 2010; JEON et al., 2004). The International Organization for Standardization indicates that a tapping machine should be used in laboratory and field measurements of impact sound insulation of floors. The machine was first developed in Germany and standardized in 1953, and is, until today, the reference indicated by ISO 10140-3 (INTERNATIONAL..., 2010) and ISO 717-2 (INTERNATIONAL..., 2013). The standards also indicate how floating floors should be constructed to achieve their best performance improving the sound insulation of apartments, where this type of noise can be a factor for discomfort between neighbors (JEON et al., 2004).

Since the standardization of the tapping machine, numerous studies have been conducted in the attempt to determine the best way to evaluate physical and auditory characteristics of floor impact noise. It is assumed that using a tapping machine to measure, the classification of the acoustical performance of different types of floors is always the same, regardless of the source and of the type of floor under test, however this approach does not work (SCHOLL, 2001).

Some authors concluded that the floor impact evaluation performed using a tapping machine does not accurately emulate the characteristics of human footsteps or low frequency impact noise (SHI; JOHANSSON; SUNDBACK, 1997; WARNOCK, 2000; NEVES E SOUZA; GIBBS, 2001; JEON, 2001; SCHOLL, 2001; BRADLEY, 2004; JEON et al., 2004; JEON; SATO, 2008; KIM et al., 2009; SCHOENWALD et al., 2010; SCHOENWALD; ZEITLER; NIGHTINGALE, 2010; YOO, 2010).

Shi, Johansson and Sundback (1997) carried a study to determine the correlation between human impact noise and other alternative impact sources, such as sand balls and sand bags, tires and the tapping machine. They concluded that a sand ball dropped from a certain height presents more similar frequency results to the human impact noise characteristics than the tapping machine.

Other researchers suggest that the frequency range for evaluation of floor impact noise using the tapping machine should be widened to $50 \mathrm{~Hz}$ instead of 100 to $3150 \mathrm{~Hz}$ as indicated on the ISO 10140, to obtain results that are more trustworthy (WARNOCK, 2000).

The rating of impact sound levels of floors is another field of research. The standard ISO 717 presents a method to determine the weighted normalized impact sound pressure level. This method is intended for rating hard and heavy floor constructions but many studies found that it generates uncertainties when the types of floor under exam are lightweight floor and soft floor coverings, thus indicating a gap in knowledge about different solutions (JEON et al., 2004).

Therefore, studies conducted up to the present moment by researchers show that the evaluation of impact noise depends both on the combined system of floor and on the type of impact source used in measurements. This implies that a particular solution for reducing the impact sound pressure level could work very efficiently when using a tapping machine and not work so well when using a different impact noise source (SCHOLL, 2001).

The objective of this study is to discuss the performance of materials against the standardized and nonstandardized source, determining which of two types of sources is most efficient in simulating real cases. To understand the behavior of the heavy impact source, the results of an objective evaluation, using thirteen samples of resilient materials were compared measuring their performance with the standard tapping machine and the alternative source. Afterwards, the non-standardized source was submitted to a subjective evaluation, correlating the results with the objective ones thus determining its efficiency as a sound source to be used in real cases simulations. The results of the subjective evaluation will be presented in further studies.

The proposed objective evaluation was carried out using impact noise insulation measurements according to ISO 10140 (INTERNATIONAL..., 2010) specifications, evaluating groups of different types of floors, resilient materials and impact sound sources (standardized tapping machine and calibrated tire), each combination being called a "sample". Several rating variables were analyzed for each of the impact sources and the results were compared in means of "performance” as a floating floor solution for impact noise. In this study the concept of performance for floating floors consists on the attenuation provided by the use of the resilient material in the sound pressure level measured in the receiving room. 


\section{Materials and methods}

The measurements carried out for this study took place in the impact chamber of the acoustics laboratory of the Federal University of Santa Maria (Brazil). The main goal was to discuss the performance of materials against the standardized and non-standardized source, determining which of two types of sources is most efficient in simulating real cases. In order to determine the efficiency of the non-standardized source, an objective evaluation was conducted, and the results are presented in this paper. Later, the non-standardized source was submitted to a subjective evaluation, correlating the results and determining its efficiency as a sound source to be used in real cases simulations.

Two types of sound sources, two types of floor, commonly found in constructions in Brazil (KLEIN; PANOSSO; PAUL, 2014) as flooring for floating floors and thirteen resilient materials were combined generating 56 samples. The components used to assemble the samples and the variables analyzed for each combination can be seen in Figure 1.

Measurements were performed using a Brüel \& Kjaer sound pressure level meter, model 2270. The complete list of equipment used in the measurements can be seen in Table 1.

The objective evaluation carried out using the standardized tapping machine generated parameters used to describe the performance of resilient materials, the Standardized impact SPL, $L_{n T}^{\prime}$, (INTERNATIONAL..., 2010) and the Weighted standardized impact SPL, $L_{n T, w}^{\prime}$, in accordance with ISO 717-2 (INTERNATIONAL..., 2013) were analyzed.

The parameters evaluated with the heavy impact source were the Maximum impact SPL, weighted fast $L_{i, F \max }$, Average maximum impact SPL, weighted fast - $L_{i, F a v g, F \max }$, obtained from the $L_{i, F \max }$ for the octave bands of 63, 125, 250 and $500 \mathrm{~Hz}$. In this study, the arithmetic average calculated was the parameter used to describe the acoustic performance of the resilient materials with the heavy impact source because it correlates satisfactorily with the subjective noise annoyance parameter (RYU et al., 2011).

\section{Figure 1 - Sound sources, types of floors, types of resilient material and parameters measured}

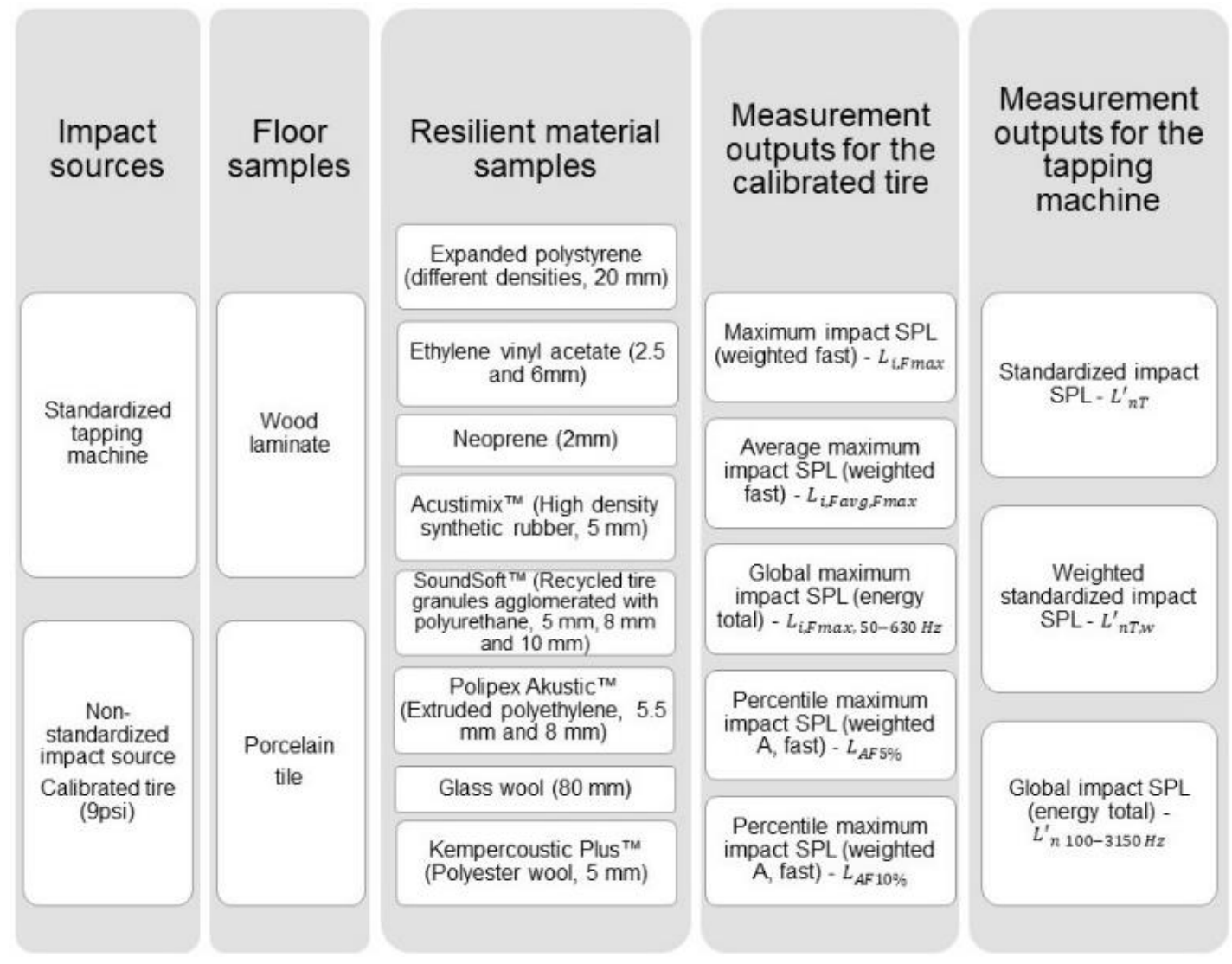


Table 1 - Equipment used in measurements

\begin{tabular}{l|l}
\hline \multicolumn{1}{c|}{ Equipment } & \multicolumn{1}{c}{ Description } \\
\hline Standardized Tapping Machine & Brüel \& Kjaer, model 3207 \\
Calibrated tire & 8 inches, calibrated with 9 [Psi] \\
Power amplifier & Brüel \& Kjaer, model 2716 \\
Omni power source & Brüel \& Kjaer, model 4292 \\
Temperature meter & CE, NF 171394-R, INSP 05/08 \\
Handheld Analyzer & Brüel \& Kjaer, model 2270 \\
Prepolarized Free-field 1/2" Microphone & Brüel \& Kjaer, model 4189 (diffuse field) \\
Sound calibrator & Brüel \& Kjaer, model 4231 \\
\hline
\end{tabular}

For the heavyweight impact source, Percentile maximum SPL data were also recorded, the parameters of interest for the study were $L_{A F 5 \%}$ and $L_{A F 10 \%}$, corresponding to the SPL exceeded in $5 \%$ and $10 \%$ of the measurement time, respectively. Both parameters weighted A.

In addition to the cited parameters, the SPL energy sum was also calculated for the third octave bands analyzed according to each sound source. For the tapping machine the frequency range was 100 to $3150 \mathrm{~Hz}$ and for the heavy impact source it was 50 to $630 \mathrm{~Hz}$. Both frequency bands were used as recommended by ISO 10140 (INTERNATIONAL..., 2010).

Also, in accordance with recommendations presented in ISO 10140-4, background noise measurements and corrections were made when necessary.

Fifty-six samples, including anchors (samples assembled with the floor cover without any resilient layer), were subdivided into four groups of measurements, each group having a different sound source and type of flooring (Figure 2). The assembly arrangement of the samples for the measurements can be seen in Figure 3.

For tests with the tapping machine, two measurements were taken for each of the four points of source location, totaling eight measurements for each sample.

For tests with the heavy impact source, four measurements were taken for each of the four points of source location, totaling sixteen measurements for each sample.

The same number of background noise SPL measurements were performed for both the tapping machine and the heavy impact source.

The data obtained with the impact noise measurements were statistically analyzed before the results were evaluated.

To obtain the single number that describes the performance of the analyzed system, the weighted standardized sound pressure level, $L_{n T, w}^{\prime}$, the curve shift method was used as indicated by ISO 717 (INTERNATIONAL..., 2013).

The global impact SPL, $L^{\prime}{ }_{n 100-3150 \mathrm{~Hz}}$ was calculated from the energy sum of the standardized impact SPL $\left(L_{n T}^{\prime}\right)$ for one-third octave bands between 100 and $3150 \mathrm{~Hz}$, through Equation 1.

$L_{\mathrm{n} 100-3150 \mathrm{~Hz}}^{\prime}=10 \log \left(\sum 10^{\frac{L_{\mathrm{n}, j}^{\prime}}{10}}\right)$

Where $L_{n, j}^{\prime}$ is the normalized impact SPL for the one-third octave bands $j(j=100,125 \ldots 3150)$.

For resilient material samples in Groups 3 and 4, tested with the calibrated tire, the resulting values of the measurement, are maximum impact SPL, $L_{i, F \max }$, measured with Fast time weighting, given the type of impact. Sixteen measurements of $L_{i, F \max }$ and sixteen measurements of background noise SPL were performed. A comparison was made to determine whether the maximum SPL values should be corrected and corrections were applied to the required values.

Resilient materials performance was evaluated as a single number quantity, using the arithmetic average of the maximum impact SPL values (RYU et al., 2011), denoted by $L_{i, F a v g, F m a x}$. The procedure for obtaining the single number involves converting the data presented in one-third octave bands into octave bands and calculating the arithmetic average of the maximum impact SPL $\left(L_{i, F \max }\right)$ between the octave bands of 63, 125, 250 and $500 \mathrm{~Hz}$ applying Equation 2. The performance of the samples can be understood as the smaller the single number, the better the performance. 
Figure 2 - Arrangement of groups for measurements

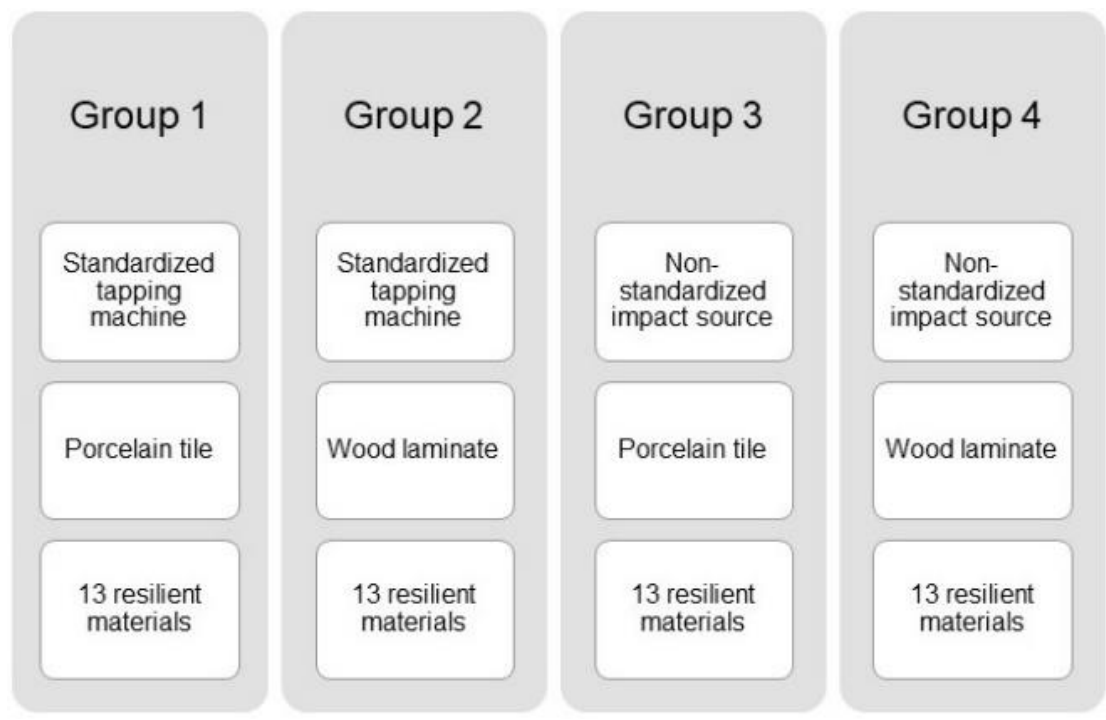

Figure 3 - Assembly of the samples for the measurements in the impact chamber

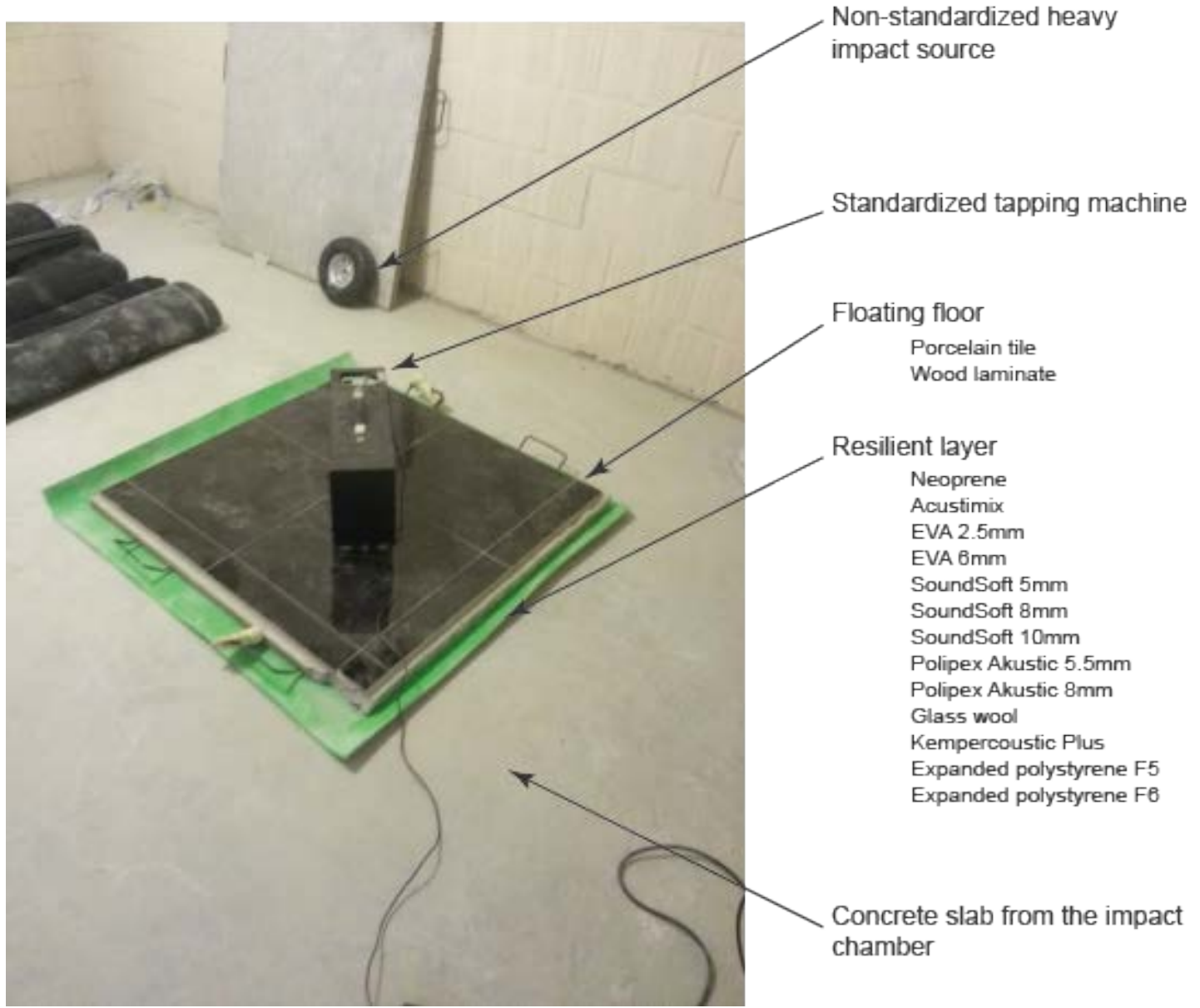

The Percentile SPL was also recorded for each of the sixteen measurements in order to determine the $L_{A F 5 \%}$ and $L_{A F 10 \%}$ for each sample excited by the heavy impact source.

$L_{i, \mathrm{Fmax}, j}=10 \log \left(\frac{1}{m} \sum_{k=1}^{m} 10^{\frac{L_{\mathrm{Fmax}, k}}{10}}\right)$

Eq. 2 
Where:

$m$ is the number of octave bands considered; and

$L_{i, F \max , j}$ is the maximum impact SPL for the octave band $j(j=63,125,250$ e $500 \mathrm{~Hz})$.

The global impact SPL $L_{i, F \max , 50-630 \mathrm{~Hz}}$ was calculated from the energy sum of the maximum impact SPL, $L_{i, F \max }$, for the one-third octave bands between 50 and $630 \mathrm{~Hz}$ through Equation 3.

$L_{i F \max 50-630 \mathrm{~Hz}}=10 \log \left(\sum 10^{\frac{L_{i, \mathrm{Fmax}, j}}{10}}\right)$

Where $L_{i, F \max , j}$ is the maximum impact SPL for the one-third octave band $j(j=50,63 \ldots 630 \mathrm{~Hz})$.

\section{Results and discussion}

Results were subdivided into four groups of analysis (Figure 2). Group 1 measurements were performed with the standard tapping machine, the porcelain tile floor and all resilient materials. Group 3 measurements were performed with the calibrated tire as a heavy impact sound source, porcelain tile floor and all resilient materials. Two samples (called anchors) assembled with the impact sources and porcelain tile floor without the resilient layer were also considered for comparison purposes.

Figure 4 shows the standardized impact SPL $L_{n T}^{\prime}$ for all floor-resilient material combinations according to frequency for Group 1. Each of the curves represents the average energy from impact SPL of the eight measurements performed. It is possible to notice that all the materials present a similar behavior regarding the analyzed frequency. It is also evident that all materials represent different levels of sound attenuation when used in combination with the porcelain tile floor and the tapping machine being the impact source used. However, the $2.5 \mathrm{~mm}$ EVA material shows an irregularity at $125 \mathrm{~Hz}$, where it causes an increase in SPL when compared to the anchor sample.

By analyzing Figure 4 it can be seen that the material that presented the best performance was the glass wool. In fact, the glass wool shows its performance detached from all other materials.

Figure 5 shows the maximum impact SPL, $L_{i, F \max }$, measured with the Fast time weighting for all resilient materials according to frequency for Group 3.

By analyzing the graph in Figure 5 it is possible to notice that almost all resilient materials behave in a similar way when associated with the porcelain tile floor and the heavy impact source. However, differing from the results with the tapping machine, in this case the levels of sound attenuation are much closer to one-another and show that all materials represent basically very similar sound attenuation. Also, the sound attenuation caused by the resilient materials when measured with the heavy impact source is lower than the one observed with the tapping machine in Group 1.

Figure 4 - Standardized impact SPL for samples measured with the standardized tapping machine, porcelain floor and all resilient materials from Group 1

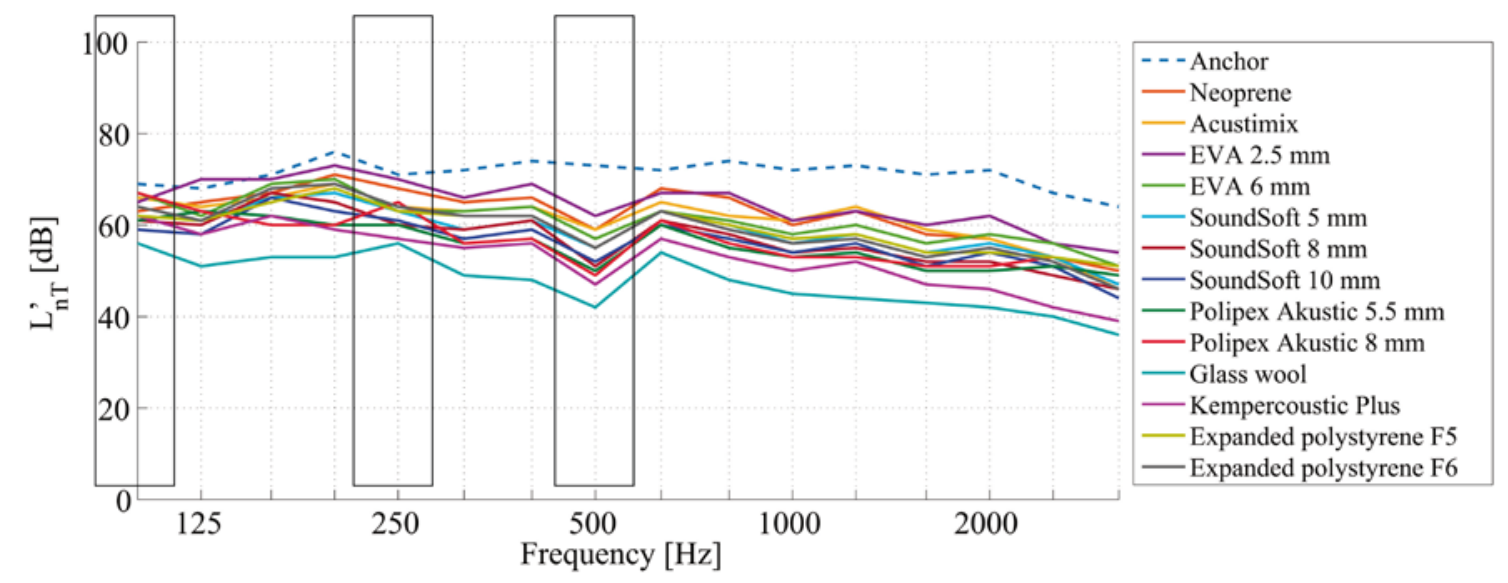


This fact is possibly due to the frequency characteristics of the sound source, which presents low frequency energy concentration. It is also possible to discern between the frequency range analyzed for the heavy impact noise source and the standardized source. The standardized source has its analysis frequency range of 100 to $3150 \mathrm{~Hz}$ as indicated by ISO 10140 . With the heavy impact source, the frequency range of 50 to $630 \mathrm{~Hz}$ was analyzed, where the noise clearly shows more energy.

In the $100 \mathrm{~Hz}$ band it is possible to see that the energy concentration is much lower in the measurements with the tapping machine (Figure 4) than with the heavy source (Figure 5). This is one of the most relevant points for measurements made with the standardized source. The most commonly reported noise as an annoyance factor in multi-story building is that of footsteps, or heavy impact noise (PARK; LEE; SEOP YANG, 2016). In this case, the tapping machine, standardized for measurements, ends up masking the performance of various materials and does not faithfully simulate heavy noise. The source demonstrates a performance from the materials that is not real for all noise when comparing its results to the heavy impact source. The same fact can be observed in the comparisons made in Figure 4 and Figure 5, in the frequencies of $250 \mathrm{and} 500 \mathrm{~Hz}$.

Also, in Figure 5 it is evident that the noise generated by the heavy impact source has a great concentration of energy at frequencies below $100 \mathrm{~Hz}$, which is not routinely evaluated using measurements with the tapping machine.

Further analysis shows that only the Kempercoustic ${ }^{\mathrm{TM}}$ resilient material, a type of recycled polyester wool, stands out timidly in performance against other materials in the range of 100 to $250 \mathrm{~Hz}$ (Figure 5). Differing from the results showed with the tapping machine, which demonstrate that the glass wool had the best performance among all materials (Figure 4).

The general performance results measured in Group 1 can be seen in Teble 2. The single number used to describe the performance of the resilient materials calculated in accordance with the method set forth in ISO 717 demonstrates that the materials exhibit diverse performances in a 50 to 67 [dB] range. The lower range represents a performance that can be considered superior for the standards currently applied in Brazilian building regulations, while the upper range represents intermediate and minimum performance. The global SPL for the medium frequency bands presents results in the range of 65 to 86 [dB]. Considering that this variable represents the energy sum of the SPL in the frequency bands of interest it is evident that the performance of the materials is not so satisfactory even though the frequencies under $100 \mathrm{~Hz}$ are not considered in the results.

The single number quantities, $L_{i, F a v g, F \max }, L_{i, F \max , 50-630 \mathrm{~Hz}}, L_{A F 5 \%}$ and $L_{A F 10 \%}$, describing the performance for samples in Group 3 can be seen in Table 3.

Figure 5 - Maximum impact SPL for samples measured with the non-standardized impact source, porcelain floor and all resilient materials from Group 3

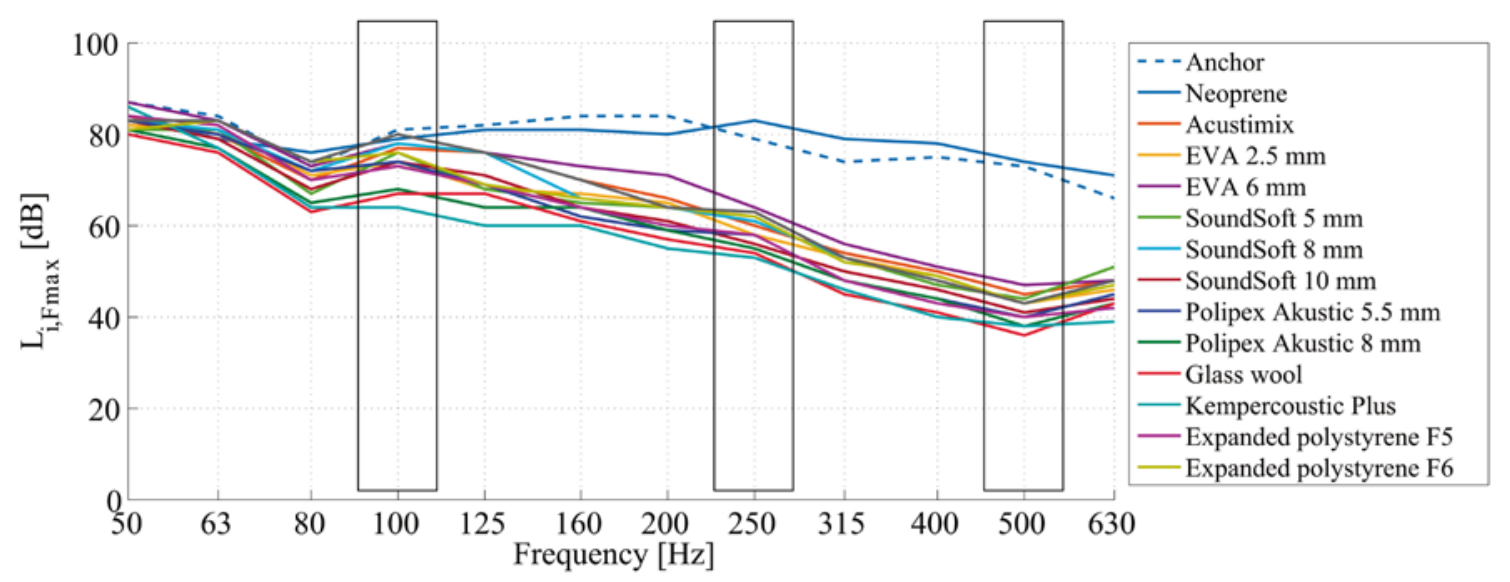


It can be noted from the analysis of Table 3 that the overall performance of the samples is low. The Average maximum impact SPL (weighted fast - $L_{i, \text { Favg,Fmax }}$ ) used as the first parameter to analyze the performance, shows that all materials had an energy average above $72[\mathrm{~dB}]$, a high value. The materials varied in results between 72 and $79[\mathrm{~dB}]$, while the anchor sample had a final performance of 82 [dB], indicating very little sound attenuation at low frequency and little advantage in using the resilient material.

Comparing the global impact sound pressure level of the measurements made with the tapping machine (Table 2) and with the non-standardized source (Table 3) it is also possible to realize that the third octave bands of 50, 63 and $80 \mathrm{~Hz}$ have a great impact on the energy sum presented by samples. In the anchor samples for example, the result with the tapping machine was $86[\mathrm{~dB}]$ while with the tire was $92[\mathrm{~dB}]$. The results for the material Polipex were also very discrepant, being $74[\mathrm{~dB}]$ with the tapping machine and $82[\mathrm{~dB}]$ with the heavy impact source.

The same conclusions are repeated when analyzing the other variables. The Percentile maximum impact SPL exceeded in 5\% of the time presented a high concentration of energy, with results varying between 71 and 79 [dB], while the Percentile maximum impact SPL exceeded in $10 \%$ of the time, showed slightly more satisfactory results in the range of 65 to $74[\mathrm{~dB}]$.

For measurements taken with the tapping machine it is possible to choose from the resilient materials at least two with optimal performance however it is not possible to do so with the measurements taken with the heavy impact source, since all materials present similar sound attenuation (Tables 2 and 3).

Table 2 - Performance results in Group 1

\begin{tabular}{|c|c|c|}
\hline Resilient material & $L_{n T, w}^{\prime}[\mathrm{dB}]$ & $L_{n 100-3150 \mathrm{~Hz}}^{\prime}[\mathrm{dB}]$ \\
\hline Anchor & 76 & 86 \\
\hline Neoprene 2 mm & 65 & 79 \\
\hline Acustimix $^{\mathrm{TM}} 5 \mathrm{~mm}$ & 64 & 78 \\
\hline EVA $2.5 \mathrm{~mm}$ & 67 & 81 \\
\hline EVA 6 mm & 64 & 78 \\
\hline SoundSoftt ${ }^{\mathrm{TM}} 5 \mathrm{~mm}$ & 62 & 76 \\
\hline SoundSoft" ${ }^{\mathrm{TM}} 8 \mathrm{~mm}$ & 60 & 74 \\
\hline SoundSoft ${ }^{\mathrm{TM}} 10 \mathrm{~mm}$ & 59 & 73 \\
\hline Polipex Akustic ${ }^{\mathrm{TM}} 5.5 \mathrm{~mm}$ & 59 & 72 \\
\hline Polipex Akustic ${ }^{\mathrm{TM}} 8 \mathrm{~mm}$ & 60 & 74 \\
\hline Glass wool $80 \mathrm{~mm}$ & 50 & 65 \\
\hline Kempercoustic Plus ${ }^{\mathrm{TM}} 5 \mathrm{~mm}$ & 55 & 70 \\
\hline Expanded Polystyrene F5 20 mm & 62 & 76 \\
\hline Expanded Polystyrene F6 20 mm & 62 & 77 \\
\hline
\end{tabular}

Table 3 - Performance results in Group 3

\begin{tabular}{|c|c|c|c|c|}
\hline Resilient material & $L_{i, F a v g, F \max }[\mathrm{dB}]$ & $L_{i, F \max , 50-630 \mathrm{~Hz}}[\mathrm{~dB}]$ & $L_{A F 5 \%}[\mathrm{~dB}]$ & $L_{A F 10 \%}[\mathrm{~dB}]$ \\
\hline Anchor & 82 & 92 & 89 & 87 \\
\hline Neoprene 2 mm & 76 & 87 & 76 & 71 \\
\hline Acustimix $^{\mathrm{TM}} 5 \mathrm{~mm}$ & 74 & 85 & 75 & 70 \\
\hline EVA $2.5 \mathrm{~mm}$ & 79 & 90 & 79 & 73 \\
\hline EVA 6 mm & 73 & 84 & 77 & 74 \\
\hline SoundSoft ${ }^{\mathrm{TM}} 5 \mathrm{~mm}$ & 76 & 87 & 75 & 68 \\
\hline SoundSoft" ${ }^{\mathrm{TM}} 8 \mathrm{~mm}$ & 75 & 86 & 72 & 65 \\
\hline SoundSoft ${ }^{\mathrm{TM}} 10 \mathrm{~mm}$ & 75 & 86 & 73 & 66 \\
\hline Polipex Akustic ${ }^{\mathrm{TM}} 5.5 \mathrm{~mm}$ & 72 & 83 & 71 & 67 \\
\hline Polipex Akustic ${ }^{\mathrm{TM}} 8 \mathrm{~mm}$ & 72 & 82 & 72 & 68 \\
\hline Glass wool $80 \mathrm{~mm}$ & 76 & 87 & 74 & 68 \\
\hline Kempercoustic Plus ${ }^{\mathrm{TM}} 5 \mathrm{~mm}$ & 76 & 87 & 75 & 70 \\
\hline Expanded Polystyrene F5 20 mm & 75 & 86 & 76 & 69 \\
\hline Expanded Polystyrene F6 20 mm & 77 & 88 & 79 & 74 \\
\hline
\end{tabular}


Group 2 measurements were performed with the standard tapping machine, laminated wood floor and all resilient materials. Group 4 measurements were performed with the calibrated tire as a heavy impact sound source, wood laminate floor and all resilient materials. Two samples (called anchors) assembled with the impact sources and wood laminate floor without the resilient layer were also considered for comparison purposes (Figure 2).

Figure 6 shows the standardized impact SPL $L_{n T}^{\prime}$ for all floor-resilient material combinations according to frequency. Each of the curves represents the average energy of the impact sound pressure levels of the eight measurements performed.

Firstly, it is clear when comparing Figure 4 with Figure 6 that the types of floor used have influence on the performance of the materials as insulation for impact noise. When using wood laminate flooring the sound attenuation obtained is higher, especially at frequencies above $400 \mathrm{~Hz}$. It is also possible to notice that the behavior of the materials is more regular throughout the spectrum of frequencies analyzed for the porcelain tile floor, while the wood laminated floor presents great decay in the sonorous attenuation from $400 \mathrm{~Hz}$, this behavior may be related to the density of the types of floors.

Figure 7 shows the maximum impact SPL $L_{i, F \max }$, measured with the fast time weighting for all resilient materials according to frequency in Group 4. It is possible to perceive the results very similar to Group 3. The materials represent little sound attenuation in the frequency range between 50 and $80 \mathrm{~Hz}$, and some resilient materials show negative performance in relation to the anchor sample in this frequency range. In Group 4 the Neoprene material presented similar behavior to the others, differently from its performance in Group 3, when associated with the porcelain floor. The glass wool material exhibits better performance when associated with laminated wood flooring.

It is also possible to notice that the performance of the resilient materials when associated with the laminated wood floor are very similar to each other, only highlighting the glass wool with performance slightly superior to the other materials in the lower frequencies (80-400 Hz). The materials EVA $2.5 \mathrm{~mm}$ and expanded polystyrene F6 presented negative performance in relation to the anchor sample in 80 and $400 \mathrm{~Hz}$.

The best performance results in this group were also the materials glass wool and Kempercoustic ${ }^{\mathrm{TM}}$, which is a type of recycled polyester wool.

The general performance results measured in Group 2 can be seen in Table 4. It shows that, when associated with wood laminate flooring, the resilient materials do not present results as diverse as with porcelain flooring. The results range between 50 and $63[\mathrm{~dB}$ ] for the unique number that describes the performance of materials according to ISO 717.

Once again, the glass wool and Kempercoustic ${ }^{\mathrm{TM}}$ presented the best results associated with the laminated wood floor, although the recycled polyester wool had a slightly better result (54 [dB] against 55 with the porcelain tile).

The global SPL measured in Group 2 presented results slightly better than the ones for Group 1, ranging from 65 to 78 [dB], also indicating a not so good performance for the overall resilient materials.

Figure 6 - Standardized impact SPL for samples measured with the standardized tapping machine, laminate floor and all resilient material from Group 2

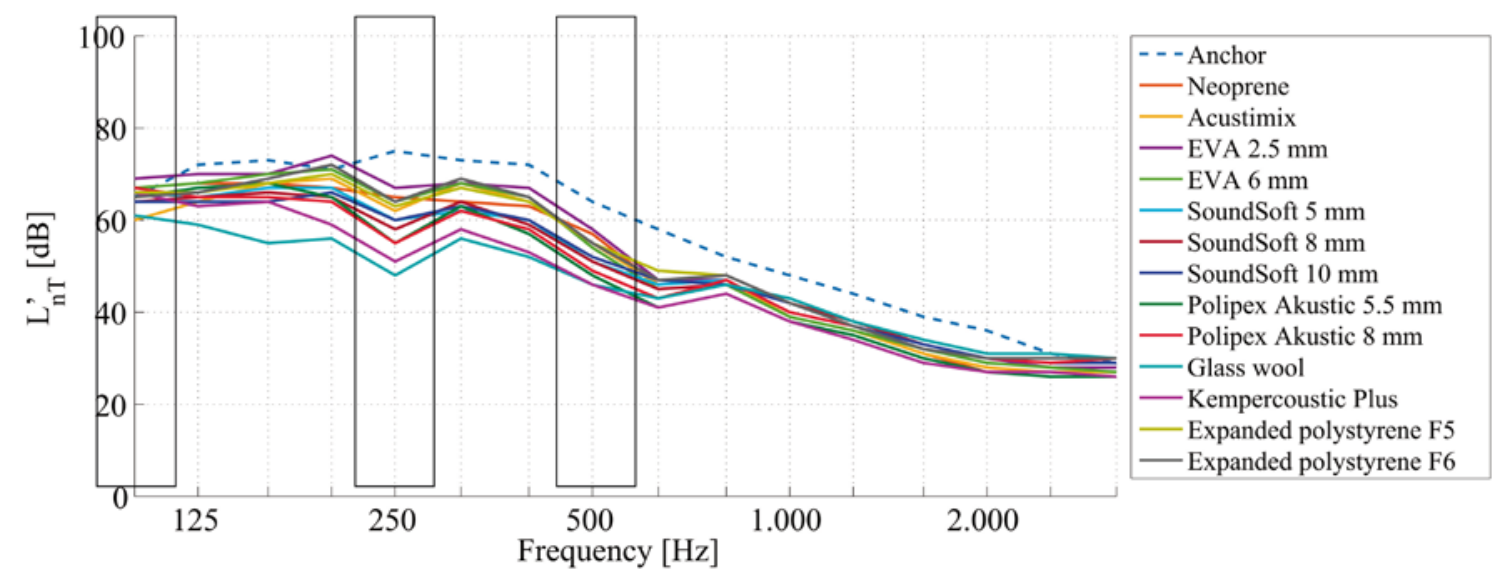


Figure 7 - Maximum impact SPL for samples measured with the non-standardized impact source, wood laminate floor and all resilient materials from Group 4

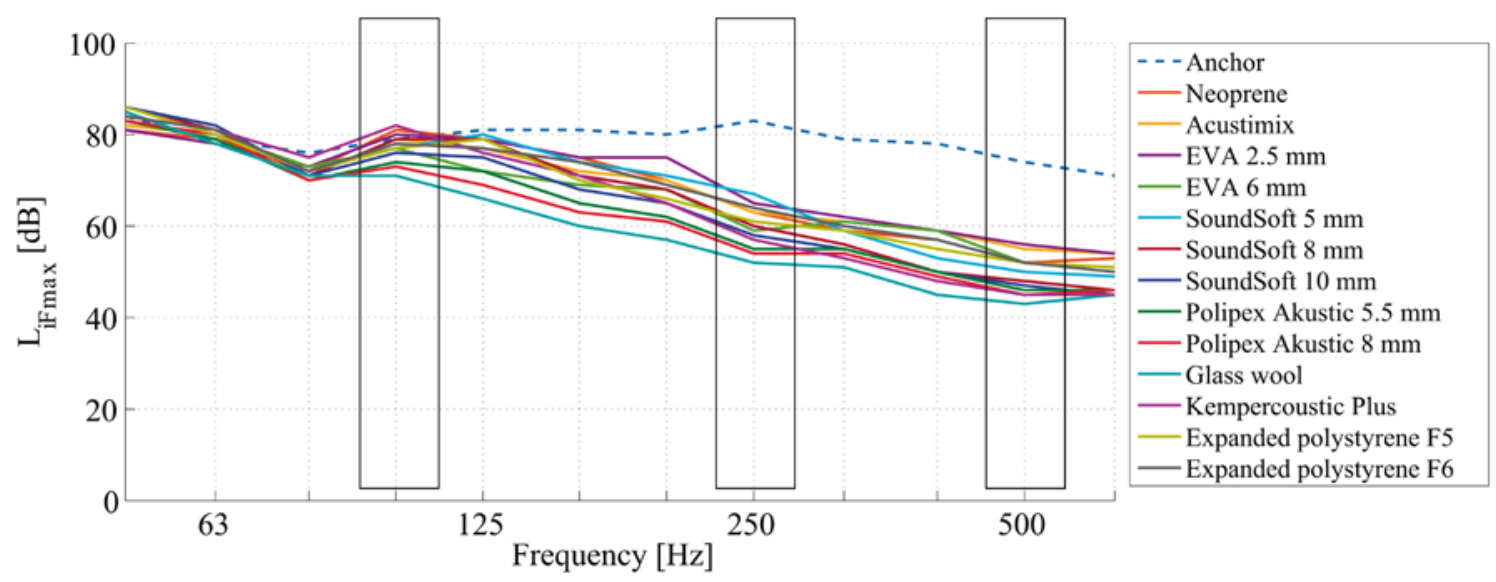

Table 4 - Performance results in Group 2

\begin{tabular}{|c|c|c|}
\hline Resilient material & $L_{n T, w}^{\prime}[\mathrm{dB}]$ & $L_{n 100-3150 \mathrm{~Hz}}^{\prime}[\mathrm{dB}]$ \\
\hline Anchor & 66 & 81 \\
\hline Neoprene $2 \mathrm{~mm}$ & 60 & 75 \\
\hline Acustimix $^{\mathrm{TM}} 5 \mathrm{~mm}$ & 59 & 75 \\
\hline EVA $2.5 \mathrm{~mm}$ & 63 & 78 \\
\hline EVA 6 mm & 62 & 77 \\
\hline SoundSoft ${ }^{\mathrm{TM}} 5 \mathrm{~mm}$ & 58 & 73 \\
\hline SoundSoft ${ }^{\mathrm{TM}} 8 \mathrm{~mm}$ & 57 & 72 \\
\hline SoundSoft ${ }^{\mathrm{TM}} 10 \mathrm{~mm}$ & 57 & 72 \\
\hline Polipex Akustic ${ }^{\mathrm{TM}} 5.5 \mathrm{~mm}$ & 58 & 73 \\
\hline Polipex Akustic ${ }^{\mathrm{TM}} 8 \mathrm{~mm}$ & 57 & 72 \\
\hline Glass wool $80 \mathrm{~mm}$ & 50 & 65 \\
\hline Kempercoustic Plus ${ }^{\mathrm{TM}} 5 \mathrm{~mm}$ & 54 & 70 \\
\hline Expanded Polystyrene F5 20 mm & 60 & 75 \\
\hline Expanded Polystyrene F6 20 mm & 61 & 77 \\
\hline
\end{tabular}

The parameters used to evaluate the performance of the samples in Group 4 can be seen in Table 5. The energy sum of the octave bands of $L_{i, F \max , 50-630 \mathrm{~Hz}}$, the percentile SPL exceeded in 5 and $10 \%$ of the measurement time ( $L_{A F 5 \%}$ and $L_{A F 10 \%}$ ) were also calculated for all samples.

The Average maximum impact SPL (weighted fast $-L_{i, F a v g, F m a x}$ ) presented for Group 4 shows even poorer performance for all the materials when compared to the samples in Group 3. The results range is of 74 to 78 $[\mathrm{dB}]$, which demonstrates very little sound attenuation in low frequency. The other variables repeated once more the same results, showing that all samples do not solve the problem of low frequency impact noise.

Table 6 shows a comparison of the global impact SPL measured in the frequency bands of $80-630 \mathrm{~Hz}$ made to illustrate the difference between the concentration of energy on results from the two impact sources.

It is possible to perceive that the difference between the energy sums of the groups is considerable, reaching 13 [dB] between Groups 2 and 4, measured with the wood laminate floor and with the resilient material Kempercoustic $^{\mathrm{TM}}$. In general, the results reported for the non-standardized impact source have higher energy total than those measured with the tapping machine. This shows that a particular solution for reducing the impact sound pressure level works very well when measurements are taken with the tapping machine but doesn’t work as well using another type of sound source (SCHOLL, 2001).

\section{Conclusion}

The objective of this study was to discuss the performance of materials against the standardized and nonstandardized source, determining which of two types of sources is most efficient in simulating real cases. 
Table 5 - Performance results in Group 4

\begin{tabular}{|c|c|c|c|c|}
\hline Resilient material & $L_{i, F a v g, F \max }[\mathrm{dB}]$ & $L_{i, F \max , 50-630 \mathrm{~Hz}}[\mathrm{~dB}]$ & $L_{A F 5 \%}[\mathrm{~dB}]$ & $L_{A F 10 \%}[\mathrm{~dB}]$ \\
\hline Anchor & 80 & 91 & 90 & 84 \\
\hline Neoprene $2 \mathrm{~mm}$ & 76 & 87 & 78 & 73 \\
\hline Acustimix $^{\mathrm{TM}} 5 \mathrm{~mm}$ & 75 & 86 & 77 & 72 \\
\hline EVA $2.5 \mathrm{~mm}$ & 76 & 87 & 79 & 74 \\
\hline EVA $6 \mathrm{~mm}$ & 76 & 86 & 76 & 71 \\
\hline SoundSoft ${ }^{\mathrm{TM}} 5 \mathrm{~mm}$ & 76 & 87 & 77 & 72 \\
\hline SoundSoft ${ }^{\mathrm{TM}} 8 \mathrm{~mm}$ & 78 & 88 & 77 & 71 \\
\hline SoundSoft ${ }^{\mathrm{TM}} 10 \mathrm{~mm}$ & 77 & 88 & 74 & 68 \\
\hline Polipex Akustic ${ }^{\mathrm{TM}} 5.5 \mathrm{~mm}$ & 75 & 86 & 72 & 65 \\
\hline Polipex Akustic ${ }^{\mathrm{TM}} 8 \mathrm{~mm}$ & 74 & 85 & 73 & 67 \\
\hline Glass wool $80 \mathrm{~mm}$ & 76 & 86 & 73 & 69 \\
\hline Kempercoustic Plus ${ }^{\mathrm{TM}} 5 \mathrm{~mm}$ & 77 & 88 & 77 & 71 \\
\hline Expanded Polystyrene F5 20 mm & 77 & 87 & 76 & 70 \\
\hline Expanded Polystyrene F6 20 mm & 77 & 88 & 77 & 71 \\
\hline
\end{tabular}

Table 6 - Comparison of the global impact SPL for all groups

\begin{tabular}{|c|c|c|c|c|}
\hline & Group 1 & Group 2 & Group 3 & Group 4 \\
\hline Resilient material & $\begin{array}{c}L_{n 80-630 ~ H z}^{\prime} \\
{[\mathrm{dB}]}\end{array}$ & $\begin{array}{c}L_{n 80-630 \mathrm{~Hz}}^{\prime} \\
\text { [dB] }\end{array}$ & $\begin{array}{c}L_{i, F \max , 80-630 ~ H z} \\
{[\mathrm{~dB}]}\end{array}$ & $\begin{array}{c}L_{i, F \max , 80-630 \mathrm{~Hz}} \\
{[\mathrm{~dB}]}\end{array}$ \\
\hline Anchor & 82 & 81 & 90 & 89 \\
\hline Neoprene 2 mm & 77 & 75 & 81 & 85 \\
\hline Acustimix $^{\mathrm{TM}} 5 \mathrm{~mm}$ & 75 & 75 & 77 & 83 \\
\hline EVA $2.5 \mathrm{~mm}$ & 79 & 79 & 82 & 85 \\
\hline EVA $6 \mathrm{~mm}$ & 77 & 77 & 76 & 80 \\
\hline SoundSoft" $5 \mathrm{~mm}$ & 73 & 74 & 82 & 83 \\
\hline SoundSoft ${ }^{\mathrm{TM}} 8 \mathrm{~mm}$ & 72 & 72 & 77 & 83 \\
\hline SoundSoft ${ }^{\mathrm{TM}} 10 \mathrm{~mm}$ & 71 & 73 & 77 & 79 \\
\hline Polipex Akustic ${ }^{\mathrm{TM}} 5.5 \mathrm{~mm}$ & 70 & 73 & 72 & 78 \\
\hline Polipex Akustic ${ }^{\mathrm{TM}} 8 \mathrm{~mm}$ & 74 & 74 & 72 & 76 \\
\hline Glass wool $80 \mathrm{~mm}$ & 63 & 66 & 69 & 75 \\
\hline Kempercoustic Plus $^{\mathrm{TM}} 5 \mathrm{~mm}$ & 69 & 71 & 76 & 84 \\
\hline Expanded Polystyrene F5 20 mm & 74 & 76 & 79 & 81 \\
\hline Expanded Polystyrene F6 20 mm & 75 & 77 & 83 & 82 \\
\hline
\end{tabular}

The performance ratings found demonstrate that a soundproof solution may or may not work, depending on the type of floor, of source and the frequency range used to evaluate the sample. This means that when simulating real cases, it is of greatest importance to determine which type of noise is of interest and the objective of the measurement, whether it is determining a performance rating according to regulations or actually solving heavy impact noise problems in dwellings.

Results from groups using the tapping machine demonstrate good performance of the resilient materials in medium and high frequencies, where the impact noise is more easily isolated. Besides that, the frequency range analyzed, as indicated by ISO 10140, does not consider low frequency. The regulations should indicate as mandatory, measurements in low frequency since there are studies that confirm that the most annoying is the heavy impact noise. Therefore, it is concluded that the tapping machine ends up masking the performance of various materials because it shows results that are not real for all sound sources and types of noise.

In general, results of groups measured with the tapping machine showed that the resilient materials under test presented performance ratings considered from minimum to superior according to currently applied Brazilian building regulations, on the other hand, results of groups measured with the non-standardized source show that all materials behave similarly and do not represent a wide range of options to solve heavy impact noise real problems such as the jumping or walking of children. This was expected and shows that the nonstandardized source may be a valid way of evaluating performance for heavy impact noise. However, to determine its efficiency it is important to correlate objective and subjective results. Further studies will show 
the correlation between the objective variables analyzed in this paper and a subjective evaluation of impact noise will be presented for the non-standardized source.

\section{References}

ARAÚJO, A. M. S.; PAUL, S.; VERGARA, E. F. Isolamento do ruído de impacto de pisos em baixa frequência com fontes normalizada e não normalizada. Ambiente Construído, Porto Alegre, v. 15, n. 1, p. 163-174, jan./mar. 2015.

BRADLEY, J. S. Sound insulation issues. In: JOING NSC-NRS WORKSHOP ON CONSTRUCTION TECHNOLOGIES, Taipei, 2004. Proceedings [...] Taipei, 2004.

HOPKINS, C. Sound Insulation. [S.l.]: Elsevier, Butterworth-Heinemann, 2007.

INTERNATIONAL ORGANIZATION FOR STANDARDIZATION. ISO 10140-3: acoustics: laboratory measurement of sound insulation of building elements: part 3: measurement of impact sound insulation. Geneve, 2010.

INTERNATIONAL ORGANIZATION FOR STANDARDIZATION. ISO 717-2: acoustics: tating of sound insulation in buildings and of building elements: part 2: impact sound insulation. Geneve, 2013.

JEON, J. Y. Subjective evaluation of floor impact noise based on the model of ACF/IACF. Journal of Sound and Vibration, v. 241, n. 1, p. 147-155, 2001.

JEON, J. Y. et al. Evaluation of floor impact sound insulation in reinforced concrete buildings. Acta Acustica United with Acustica, v. 90, p. 313-318, 2004.

JEON, J. Y.; RYU, J. K.; LEE, P. J. A quantification model of overall dissatisfaction with indoor noise environment in residential buildings. Applied Acoustics, v. 71, p. 914-921, 2010.

JEON, J. Y.; SATO, S. Annoyance caused by heavyweight floor impact sounds in relation to the autocorrelation function and sound quality metrics. Journal of Sound and Vibration, v. 311, p. 767-785, 2008.

KIM, K. W. et al. Correlation between dynamic stiffness of resilient materials and heavyweight impact sound reduction level. Building and Environment, v. 44, n. 8, p. 1589-1600, 2009.

KLEIN, M. E.; PANOSSO, A. D. S.; PAUL, S. Tempo de reverberação em salas comuns de residências típicas do sul. In: CONGRESO IBEROAMERICANO DE ACÚSTICA, 9., Valdivia, 2014. Anais [...] Valdivia, 2014.

NEVES E SOUZA, A.; GIBBS, B. M. Low frequency impact sound transmission in dwellings through homogeneous concrete floors and floating floors. Applied Acoustics, v. 72, n. 4, p. 177-189, 2001.

NIEMANN, H.; MASCHKE, C. WHO LARES - Final report - Noise effects and morbidity. World Health Organization and Berlin Center of Public Health, 2004.

PARK, S. H.; LEE, P.; SEOP YANG, K. Perception and reaction to floor impact noise in apartment buildings: a qualitative approach. Acta Acustica united with Acustica, v. 102, n. 5, p. 902-911, 2016.

RYU, J. et al. Relation between annoyance and single-number quantities for rating heavy-weight floor impact sound insulation in wooden houses. The Journal of the Acoustical Society of America, v. 129, p. 3047-3055, 2011.

SCHOENWALD, S. et al. Approaches for estimating flanking transmission for heavy impact sources. In: INTER-NOISE AND NOISE-CON CONGRESS AND CONFERENCE, Lisbon, 2010. Proceedings [...] Lisboa: Institute of Noise Control Engineering, 2010.

SCHOENWALD, S.; ZEITLER, B.; NIGHTINGALE, T. R. T. Influence of receive room properties on impact sound pressure level measured with heavy impact sources. in: EAA - EUROREGIO CONGRESS ON SOUND AND VIBRATION, Ljubljana, 2010. Proceedings [...] Ljubliana, 2010.

SCHOLL, W. Impact sound insulation: the standard tapping machine shall learn to walk! Building Acoustics, v. 8, p. 245-256, 2001.

SHI, W.; JOHANSSON, C.; SUNDBACK, U. An investigation of the characteristics of impact sound sources for impact insulation measurement. Applied Acoustics, v. 51, p. 85-108, 1997. 
WARNOCK, A. Low-frequency impact sound transmission through floor systems. In: INTER.NOISE 2000: INTERNATIONAL CONGRESS AND EXHIBITION ON NOISE CONTROL ENGINEERING, 29., Nice, 2000. Nice, Proceedings [...] 2000.

YOO, S. Measurement of sound field for floor impact sounds generated by heavy/soft impact sources. Acta Acustica united with Acustica, v. 96, n. 4, p. 761-772, 2010.

Andriele da Silva Panosso

Programa de Pós-Graduação em Engenharia Civil | Universidade Federal de Santa Maria | Av. Roraima, 1000 | Santa Maria - RS - Brasil | CEP 97105-900 | Tel.: (55) 3220-8837 | E-mail: andrielep@gmail.com

\section{Stephan Paul}

Programa de Pós-Graduação em Engenharia Civil | Universidade Federal de Santa Maria | E-mail: stephan.paul.acoustic@gmail.com

\section{Ambiente Construído}

Revista da Associação Nacional de Tecnologia do Ambiente Construído

Av. Osvaldo Aranha, 99 - 30 andar, Centro

Porto Alegre - RS - Brasil

$$
\text { CEP } 90035-190
$$

Telefone: +55 (51) 3308-4084

Fax: +55 (51) 3308-4054

www. seer. ufrgs. br/ ambienteconstruido

E-mail: ambienteconstruido@ufrgs.br 